Review article

\title{
RECENT ADVANCES IN MANAGMENT OF CATARACT SURGERY COMPLICATIONS
}

\author{
Mohammed, O. \\ Ophthalmology dept., Faculty of Medicine, Sohag Univ., Sohag, Egypt \\ E-mail: usama2a@mailcity.com
}

\begin{abstract}
Cataract disease is the main cause of the global burden of visual impairment. As the technology advances, phacoemulsification becomes the surgical procedure of choice for cataract treatment; However, phacoemulsification is not a completely safe procedure and has many complications including Endophthalmitis, Cystoid macular edema, Endothelial cells loss, Vitreous loss, and retinal detachment. The aim of this review is to discuss the recent advances in management of cataract surgery complications.
\end{abstract}

Keywords: Cataract surgery, Phacoemulsification, Complications, Endophthalmitis, Cystoid macular edema, Endothelial cells loss, Vitreous loss

\section{Introduction}

Cataract disease is mainly responsible for about half of the global burden of visual impairment. Recently, phacoemulsification is the surgical procedarn of choice routinely which provides excellent visual and safety outcome. About 18 million cataract surgeries are

\section{Endophthalmitis Prophylaxis}

Endophthalmitis is the most serious postoperative complication of phacoemulsification. Postoperative endophthalmitis is caused by entry of microorganisms into the eye during or after the surgical procedure [3]. Different methods are used to avoid endophthalmitis, Injecting intracameral antibiotics at the end of surgery is intended to kill bacterial performed all over the world every year [1]. However, phacoemulsification is not a perfect procedure and complications such as endophthalmitis, cystoid macular edema, endothelial cell damage, vitreous loss and retinal detachment remain sight threatening concerns [2].

microbes that have been introduced during the procedure [4]. The most commonly used antibiotics for intracameral prophylaxis are cephalosporins (cefuroxime and cefazolin), vancomycin, and moxifloxacin. Cefuroxime is a second-generation cephalosporin. The ESCRS study recommended intracameral injection of cefuroxime $(1.0 \mathrm{mg}$ in $0.1 \mathrm{ml})$ at the time of 
cataract surgery for prevention of postoperative endophthalmitis [5]. Despite of different Opinions, the drug became available for commercial use (Aprokam, Thea group, Clermont Ferrad, France) and it is used both in Europe (where the drug is approved) and in the USA (offlabel use) [4]. Moxifloxacin is a fourthgeneration fluoroquinolone that was

\section{Cystoid Macular Edema}

Postoperative cystoid macular edema (PCME) is the most common cause of decreased postoperative visual results after cataract surgery $[7,8]$. Risk factors of pseudophakic CME have been thoroughly studied. Diabetes, hypertension, epiretinal membrane, uveitis, glaucoma, and vascular occlusion can be linked to the incidence of pseudophakic CME [9-11]. Topical nonsteroidal anti-inflammatory drugs (NSAIDs) [12], intravitreal anti-vascular endothelial growth factor (anti-VEGF) injections [13], intravitreal steroids [14] and oral acetazolamide [15] have all been used in the treatment of pseudophakic cystoid macular edema with different results. Recurrence

\section{Endothelial Cells Loss}

The endothelial cell count is known to decline with age. With increasedlife expectancy and also, most of patients undergoing phacoemulsification belong to the elderly age group; endothelial cell loss during surgery becomes an important factor [20]. The choice of surgical incision plays an important role in the efficacy of surgery, as the incision damages the surrounding tissues. The size of microincisional phacoemulsification surgery incisions ranges from 1.8 $\mathrm{mm}$ to $2.2 \mathrm{~mm}$, whereas standard-incision phacoemulsification surgery incisions range from $2.8 \mathrm{~mm}$ to $3.2 \mathrm{~mm}$ [21]. In a study of Wang L et al, [22] they compared

\section{Vitreous loss}

Vitreous loss during phacoemulsification is associated with low visual results. Experienced surgeons who performed a high volume of Phaco operations have approved for topical ophthalmic use in 2003. Intracameral moxifloxacin achieves bactericidal levels 10 times more than the most resistant bacteria for a limited time period; also, due to its potent dosedependent activity at low concentrations of injection, in addition that it remains bactericidal for a longer period than cefuroxime [6].

of PCME after successful therapy is very low, but still some cases are refractive to standard therapy [16]. Intravitreal dexamethasone (DEX) implant has been used as a new therapy in PCME in recent years [17]. In a study of Kakkassery V et al, [18] they found that the use of DEX in PCME resulted in significant improvements in visual acuity and central foveal thickness. Recently, in a study of Maleki A et al, [19]. They studied the efficacy and safety of interferon alpha $2 b$ in the treatment of PCME resistant to conventional therapy with favorable results.

the efficacy between coaxial microincision and standard-incision phacoemulsification in patients with age-related cataracts in a meta-analysis study, however, they found that there is no difference between both groups. As regards the use of femtosecond laser in cataract surgery, in a study of Khan MS et al, [23] they compared the change in endothelial cell count after femtosecond laser-assisted cataract surgery versus conventional phacoemulsification, they found that femtosecond laser in cataract surgery is a safe and effective modality for cataract treatment and it induces significantly less endothelial cell loss than conventional phacoemulsification.

lower rates of vitreous loss [24]. The predisposing factors for vitreous loss may be classified into patient-related, surgeonrelated, intraoperative factors, and to 
devices/machines-related [25]. There are recent techniques available to anterior and posterior segment surgeons in posterior capsule rupture. Endoillumination facilitate visualization during anterior vitrectomy and the implanted IOL may be used as a

\section{Retinal Detachment}

Retinal detachmentis one of the most frequent sight-threatening complications of modern cataract surgery and complicates about $1 \%$ of all cataract operations operated in Western countries [27,28] multiple risk factors are implicated, including patient factors (young age, male sex, and long axial length) $[29,30]$. In a study of Daien V et al, [31] they assessed the incidence, risk factors, and impact of age on retinal detachment (RD) after cataract surgery in France, They provide a list of risk factors for RD onset: high myopia, young age, capsular rupture, history of eye trauma,

\section{References}

1.Rao, G., Khanna, R., Payal, A. The global burden of cataract. Curr Opin Ophthalmol. 2011; 22: 4-9.

2. Clark, A., Morlet. N., Ng, J., Preen, B., Semmens, J. Whole population trends in complica-tions of cataract surgery over 22 years in Western Australia. Ophthalmology 2011; 118: 1055-1061.

3. Shimada, H., Arai, S., Nakashizuka, H., Hattori, T., Yuzawa, M. Reduced anterior chamber contamination by frequent surface irrigation with diluted iodine solutions during cataract surgery. Acta Ophthalmol. 2017. [Epub ahead of print].

4. Chang, D., Braga-Mele, R., Henderson, B., Mamalis, N., Vasavada, A., ASCRS Cataract Clinical Committee. Antibiotic prophylaxis of postoperative endophthalmitis after cataract surgery: results of the 2014 ASCRS member survey. J Cataract Refract Surg. 2015; 41: 1300-1305.

5. Das, T., Sharma, S., Muralidhar, A. Endopthalmitis Research Group. Effect of vancomycin on Staphylococcus epi- pupillary barrier to prevent further loss of lens fragments. Also, early return to the operating room and small-gauge pars plana procedures may reduce patient morbidity [26].

extra capsular extraction technique, male gender, and diabetes. Young age was also an additional risk factor in myopic patients. Pars plana vitrectomy with phacofragmentation is the preferred technique of treatment of dropped lens fragments [32,33]. With availability of new fragmatomes, most of cases can be treated successfully with satisfactory results. Perfluorocarbon liquids (PFCL) are an effective surgical method for prevention of this damage. But retained PFCL bubbles are associated with multiple complications. Torsional phacoemulsification has a less repulsive action on nuclear piece.

dermidis adherence to poly (methyl methacrylate) intraocular lenses. $\boldsymbol{J}$ Cataract Refract Surg. 2002; 28: 703-708.

6. Arshinoff, S., Modabber, M. Dose and administration of intracameral moxifloxacin for prophylaxis of postoperative endophthalmitis. J Cataract Refract Surg. 2016; 42: 1730-1741.

7. Belair, M., Kim, S., Thorne, J., Dunn, J., Kedher, S., Brown, D., Jabs, D. Incidence of cystoid macular edema after cataract surgery in patients with and without uveitis using optical coherence tomography. $\boldsymbol{A m} \boldsymbol{J}$ Ophthalmol 2009; 148: 128-135.

8. Greenberg, P., Tseng, V., Wu, W., Liu, J., Jiang, L., Chen, C., Scott, I., Friedmann, P. Prevalence and predictors of ocular complications associated with cataract surgery in United States veterans. Ophthalmology 2011; 118: 507-514.

9. Estafanous, M., Lowder, C., Meisler, D., Chauhan, R. Phacoemulsification cataract extraction and posterior chamber lens implantation in patients 
with uveitis. Am J Ophthalmol 2001; 131: 620-625.

10. Tso, M. Pathology of cystoid macular edema. Ophthalmology 1982; 89: 902-915.

11. Krishna, R., Meisler, D., Lowder, C., Estafanous, M., Foster, R. Longterm follow-up of extracapsular cataract extraction and posterior chamber intraocular lens implantation in patients with uveitis. Ophthalmology 1998; 105: 1765-1769.

12. Shelsta, H., Jampol, L. Pharmacologic therapy of pseudophakic cystoid macular edema; 2010 update. Retina. 2011; 31 (1): 4-12.

13. Falavarjani, K., Parvaresh, M., Modarres, M. Intravitreal bevacizumab for pseudophakic cystoid macular edema; a systematic review. J Ophthalmic Vis Res. 2012; 7 (3): 235-239.

14. Heier, J., Topping, T., Baumann, W. Ketorolac versus prednisolone versus combination therapy in the treatment of acute pseudophakic cystoid macular edema. Ophthalmology. 2000; 107 (11): 2034-2038.

15. Ćurković, T., Vukojević, N., Bu can, K. Treatment of pseudophakic cystoid macular oedema. Coll Antropol. 2005; 29 (1): 103-105.

16. Landre, C., Zourdani, A., Gastaud, P., Baillif, S. Treatment of postoperative cystoid macular edema (Irvine-Gass syndrome) with dexamethasone 0.7 mg intravitreal implant. Journal Français d'Ophtalmologie 2016; 39 (1): 5-11,

17. Khurana, R., Palmer, J., Porco, T., Wieland, M. Dexamethasone intravitreal implant for pseudophakic cystoid macular edema in patients with diabetes. Ophthalmic Surg Lasers Imaging Retina 2015; 46 (1): 56-61.

18. Kakkassery, V., Schultz, T., Wunderlich, M., Schargus, M., Dick, H., Rehrmann, J. Evaluation of predictive factors for successful intravitreal dexamethasone in pseudophakic cystoid macular edema. J Ophthalmol. 2017; 2017:4625730.
19. Maleki, A., Aghaei, H., Lee, S. Topical interferon alpha $2 \mathrm{~b}$ in the treatment of refractory pseudophakic cystoid macular edema. American Journal of Ophthalmology Case Reports 2018; 10: 203-205.

20. Yee, R., Matsuda, M., Schultz, R., Edelhauser, H. Changes in the normal corneal endothelial cellular pattern as a function of age. Curr Eye Res. 1985; 4 (6): 671-678.

21. Zhao, L., Yan, H. Advantages and disadvantages of microincision cataract surgery. Int J Ophthalmol. 2012; 12 (12): 2306-2308.

22. Khan, M., Habib, A., Ishaq, M., Yaqub, M. Effect of femtosecond laser-assisted cataract surgery (FLACS) on endothelial cell count. $\boldsymbol{J}$ Coll Physicians Surg Pak. 2017; 27 (12): 763-766.

23. Jacobs, P., Vitreous loss during cataract surgery: Prevention and optimal management. Eye 2008; 22 (10): 1286-1289.

24. Chakrabarti, A., Nazm, N. Posterior capsular rent: Prevention and management. Indian J Ophthalmol. 2017; 65 (12): 1359-1369.

25. Chiu, C. 2013 update on the management of posterior capsular rupture during cataract surgery. Curr Opin Ophthalmol. 2014; 25 (1): 26-34.

26. Sheu, S., Ger L., Chen J. Male sex as a risk factor for pseudophakic retinal detachment after cataract extraction in Taiwanese adults. Ophthalmology 2007; 114 (10): 1898-1903.

27. Clark, A., Morlet, N., Ng, J., Preen, D., Semmens, J. Whole-population trends in complications of cataract surgery over 22 years in Western Australia. Ophthalmology 2011; 118 (6): 1055-1061.

28. Sheu, S., Ger, L., Ho, W. Late increased risk of retinal detachment after cataract extraction. $\boldsymbol{A m} \boldsymbol{J}$ Ophthalmol. 2010; 149 (1): 113-119.

29. Lois, N.,Wong, D. Pseudophakic retinal detachment. Surv Ophthalmol. 2003; 48 (5): 467-487. 
30. Daien, V., Le Pape A, Heve D, Carriere I, Villain M. Incidence, risk factors, and impact of age on retinal detachment after cataract surgery in France: A national population study. Ophthalmology 2015; 122 (11): 2179-2185.

31. Ho, L., Walsh, M., Hassan, T. 25Gauge pars plana vitrectomy for retained lens fragments. Retina 2010; 30: 843-849.

32. Soliman, M., Eid, M., Shalaby, K., Hegazy, H. Intravitreal phacoemuls- ification with pars plana vitrectomy for management of posteriorly dislocated nucleus or lens fragments. Eur J Ophthalmol. 2010; 20: 115-119.

33. Verma, L. Gogoi, M., Tewari, H., Kumar, A., Talwar, D. Comparative study of vitrectomy for dropped nucleus with and without the use of perfluorocarbon liquid. Clinical, electrophysiological and visual field outcomes. Acta Ophthalmol Scand 2001; 79: 354-358. 